\title{
Thalamic Ryanodine Receptors Are Involved in Controlling the Tonic Firing of Thalamocortical Neurons and Inflammatory Pain Signal Processing
}

\author{
Eunji Cheong, ${ }^{1,2}$ Chanki Kim, ${ }^{1}$ B. Jiwon Choi, ${ }^{1}$ Minjeong Sun, ${ }^{1}$ and Hee-Sup Shin ${ }^{1,2}$ \\ ${ }^{1}$ Center for Neural Science, Korea Institute of Science and Technology, Seoul, 136-791, Republic of Korea, and ${ }^{2}$ Department of Neuroscience, University of \\ Science and Technology, Daejon 305-333, Republic of Korea
}

Ryanodine receptors (RyRs) are highly conductive intracellular $\mathrm{Ca}^{2+}$ release channels which are widely expressed in the CNS. They rapidly increase the intracellular $\mathrm{Ca}^{2+}$ concentrations in neuronal cells in response to $\mathrm{Ca}^{2+}$ influx through voltage-gated $\mathrm{Ca}^{2+}$ channels. A previous study reported that RyRs were expressed in thalamocortical (TC) neurons, but their physiological function has remained elusive. Here, we show that the activation of RyRs in TC neurons in mice decreases their tonic firing rate while blocking them induces the opposite response. Furthermore, activation of RyRs in ventroposteriomedial/ventroposteriolateral nuclei reduces the behavioral responses to inflammatory pain and blocking them increases the responses. This study highlights the importance of the intracellular $\mathrm{Ca}^{2+}$ release via RyRs in controlling the excitability of TC neurons and in inflammatory pain signal processing in the thalamus.

\section{Introduction}

The two major $\mathrm{Ca}^{2+}$ sources in neurons are the $\mathrm{Ca}^{2+}$ influx from the extracellular space and the $\mathrm{Ca}^{2+}$ release from internal storage (Berridge et al., 2003). The latter occurs through ryanodine receptors (RyRs) or inositol-1,4,5-triphosphate receptors ( $\mathrm{IP}_{3} \mathrm{Rs}$ ). RyRs, triggered by the $\mathrm{Ca}^{2+}$ influx through voltage gated $\mathrm{Ca}^{2+}$ channels on the plasma membrane, rapidly release $\mathrm{Ca}^{2+}$ into the cytosolic matrix with a large conductance. Therefore, this $\mathrm{Ca}^{2+}$ induced $\mathrm{Ca}^{2+}$ release (CICR) by RyRs acts to boost the intracellular $\mathrm{Ca}^{2+}$ increase in an immediate response to external stimuli. Ryanodine receptors are widely expressed in neuronal cells in the CNS (Furuichi et al., 1994). Recently, evidence is accumulating that the thalamocortical (TC) neurons in rodents also express both types of intracellular $\mathrm{Ca}^{2+}$ channels, RyRs and $\mathrm{IP}_{3} \mathrm{Rs}$ (Budde et al., 2000; Pape et al., 2004). However, the physiological function of RyRs in TC neurons has not yet been determined.

The thalamus plays a pivotal role in sensory signal processing, integrating sensory inputs from the periphery and inputs from other brain regions, and then sending the integrated information to the cortex (Sherman and Guillery, 1996). The firing modes of TC neurons have been implicated in reflecting the status of signal transmission from the thalamus to the cortex (McCormick and von Krosigk, 1992). In addition, it has been reported that RyRs are highly expressed in ventroposteriomedial/ventroposteriolateral (VPM/VPL) nuclei in the thalamus (Furuichi et al., 1994),

\footnotetext{
Received June 22, 2010; revised Nov. 12, 2010; accepted Nov. 21, 2010.

This work was supported by the National Honor Scientist Program of Korea, and the Center of Excellence Program of the Korea Institute of Science and Technology.

Correspondence should be addressed to Dr. Eunji Cheong, Center for Neural Science, Korea Institute of Science and Technology, 39-1 Hawolgok-dong, Seongbuk-gu, Seoul 136-791, Republic of Korea. E-mail: eunjicheong@ kist.re.kr.

DOI:10.1523/JNEUROSCI.3203-10.2011

Copyright $\odot 2011$ the authors $\quad 0270-6474 / 11 / 311213-06 \$ 15.00 / 0$
}

which are the main relay nuclei for innocuous tactile information but also contain neurons which respond to noxious stimuli and relay pain information to the cortex (Peschanski et al., 1983; Willis and Westlund, 1997). Therefore, we examined a possible role for RyRs in the control of TC firing and their potential function in the pain sensory relay. The results suggest that RyRs in the VPM/VPL nuclei play a substantial role in controlling the excitability of TC neurons and affecting pain signal processing.

\section{Materials and Methods}

Animals. All experiments used male F1 hybrid mice generated by the mating of two inbred strains, 129/Sv and C57BL/6J. Animal care and all experiments were conducted under the ethical guidelines of the Institutional Animal Care and Use Committee of the Korea Institute of Science and Technology.

Preparation of brain slices and acutely dissociated neuronal cells. The firing patterns of TC neurons were recorded in acutely isolated brain slices from $\sim 4$-week-old mice. The brain was sectioned in the coronal plane in ice-cold slicing solution (in mm: $124 \mathrm{NaCl}, 26 \mathrm{NaHCO}_{3}, 1.25$ $\mathrm{NaH}_{2} \mathrm{PO}_{4}, 5 \mathrm{MgCl}_{2}, 1 \mathrm{CaCl}_{2}, 3 \mathrm{KCl}$, and 10 glucose) and incubated for $1 \mathrm{~h}$ at room temperature before use. $\mathrm{Ca}^{2+}$ imaging experiments were performed using acutely dissociated cells from 14- to 21-d-old mice. Brain slices were treated at $37^{\circ} \mathrm{C}$ in an oxygenated HEPES-buffered solution (in mM: $150 \mathrm{NaCl}, 3 \mathrm{KCl}, 2 \mathrm{CaCl}_{2}, 10$ HEPES, $2 \mathrm{MgCl}_{2}$, and 10 glucose, $\mathrm{pH}$ $\sim 7.4$ and $320-330 \mathrm{mOsm}$ ) containing $2 \mathrm{mg} / \mathrm{ml}$ protease XIV (Sigma) for $10 \mathrm{~min}$, followed by an incubation at room temperature for $5 \mathrm{~min}$. After the enzymatic treatment, slices containing the VPM/VPL nuclei were dissected by scalpel cuts, and cells were triturated with fire-polished Pasteur pipettes.

Intracellular $\mathrm{Ca}^{2+}$ imaging. fura-2AM (Invitrogen) was used as the fluorescent $\mathrm{Ca}^{2+}$ indicator. Briefly, acutely dissociated cells were loaded with fura-2 AM $(5 \mu \mathrm{g})$ mixed with $5 \mu \mathrm{l}$ of pluronic acid in HEPESbuffered solution and plated onto poly-D-lysine-coated coverslips in a chamber placed on an inverted microscope (TE3000, Nikon). Then cells were perfused continuously with the buffer at a rate of $2 \mathrm{ml} / \mathrm{min}$. Cells were illuminated with excitation wavelengths $(340 / 380 \mathrm{~nm})$ provided by 
the IonOptix chopper equipped with a xenon light source and a computer-controlled electronic shutter (Photon Technology International). The intracellular $\mathrm{Ca}^{2+}$ concentration was measured by an intensified CCD camera (PTI IC-200, Photon Technology International) coupled to a microscope and a computer. NMDA, ryanodine, dantrolene and caffeine were purchased from Sigma.

Reverse-transcriptase-PCR analysis. Total RNA was isolated from both the whole brain and the VPM/VPL nuclei using RNA isolation reagents (TRI Reagent, Molecular Research Center). To produce cDNA, one microgram of total RNA was reverse-transcribed with M-MLV reverse transcriptase (Invitrogen) using oligo(dT) priming. The PCR primers and PCR conditions are shown in supplemental method (available at www.jneurosci.org as supplemental material).

Whole-cell patch clamping. The firing patterns of TC neurons in brain slices were recorded under the current-clamp mode in ACSF solution (in mm: $124 \mathrm{NaCl}, 26 \mathrm{NaHCO}_{3}$, $1.25 \mathrm{NaH}_{2} \mathrm{PO}_{4}, 1.3 \mathrm{MgSO}_{4}, 2.4 \mathrm{CaCl}_{2}, 3 \mathrm{KCl}$, and 10 glucose) bubbled with $95 \% \mathrm{O}_{2} / 5 \%$ $\mathrm{CO}_{2}$. Patch electrodes (4-6 M $\Omega$ ) fabricated from borosilicate glass (GC150F-10, Warner Instruments) were filled with an intrapipette solution (in mM: $140 \mathrm{~K}$-gluconate, $10 \mathrm{KCl}, 1$ $\mathrm{MgCl}_{2}, 10$ HEPES, 0.02 EGTA, $4 \mathrm{Mg}$-ATP, and $0.3 \mathrm{Na}_{2}-\mathrm{GTP}$, with $\mathrm{pH}$ 7.35). Signals were amplified with a Multiclamp 700-A amplifier (Molecular Devices) and analyzed using pCLAMP 9.2 and MiniAnalysis software (Synaptosoft).

Drug infusion via micro-osmotic pump implantation. For drug infusion into the brain, micro-osmotic pumps (Alzet) were placed in the mouse brain with the tips targeting the thalamic VPM/VPL nuclei (anteroposterior, 1.7; lateral, \pm 1.7 ; ventral, $3.5 \mathrm{~mm}$ ) using a stereotaxic device (Kopf Instruments) as previously described (Kim et al., 2003). The infusion implant placements were confirmed by postmortem histology.

Visceral pain tests and formalin-induced pain test. Visceral pain tests were performed as previously described (Kim et al., 2003). Mice were placed in an acrylic cylinder positioned over a mirror angled at $45^{\circ}$ to allow the observer an unobstructed view of the paws and abdomen. Visceral pain was induced by an injection of acetic acid ( $0.6 \%$ in saline) into the peritoneum at $6 \mathrm{ml} / \mathrm{kg}$. The writhing responses, including stretching and constriction, were counted to quantify the pain responses. The formalin-induced pain test was performed by a previously described protocol (Berridge et al., 2003). Ten microliters of $2.0 \%$ formalin in saline were injected subcutaneously into the dorsal surface of the left hindpaw. The time spent in pain responses such as licking, biting, and shaking was quantified.

Mechanical pain test. Mechanical pain tests were performed as previously described (Chapman et al., 1985; Kim et al., 2001). The mechanical threshold was measured using calibrated von Frey filaments (Stoelting) and was defined as the bending force, in grams, at which the mouse withdrew its hindpaw. The response score was assessed as the total number of hindpaw withdrawals in 10 trials for each filament.

Thermal pain test. Responses to thermal stimuli were measured by Hargreaves' method (Hargreaves et al., 1988; Kim et al., 2001) using a plantar test apparatus. Hindpaw withdrawal latency to infrared thermal stimuli at a 40 intensity level (an arbitrary unit in the machine) was measured after $1 \mathrm{~h}$ habituation. Stimuli were delivered 5 times to the hindpaw at 5 min intervals.

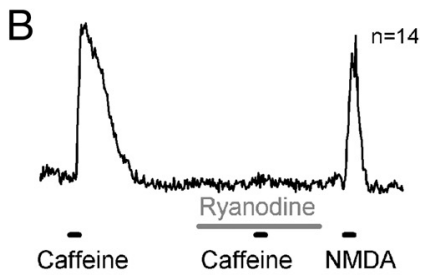

D
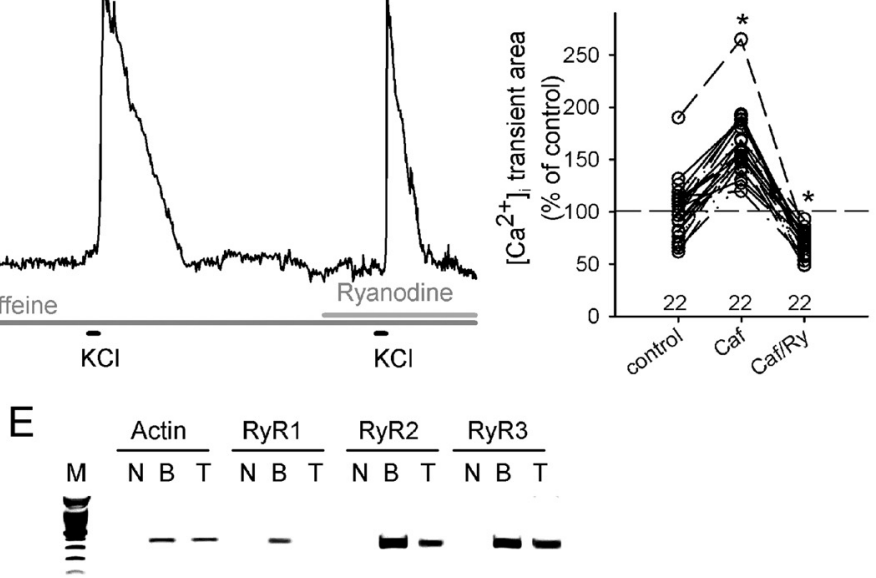

Figure 1. Caffeine evokes intracellular calcium transients via $\mathrm{Ca}^{2+}$ release through RyRs in TC neurons. $A$, A representative trace of fura-2 ratiometric $\mathrm{Ca}^{2+}$ imaging on TC neurons acutely dissociated from VPM/VPL nuclei. $\mathrm{Ca}^{2+}$ transients were evoked by an application of $10 \mathrm{~mm}$ caffeine either in $2 \mathrm{~mm} \mathrm{Ca}{ }^{2+}$ buffer or $\mathrm{Ca}^{2+}$-free buffer, which indicates that a $\mathrm{Ca}^{2+}$ transient was via the coapplication of caffeine $(0.5 \mathrm{~mm})$ and ryanodine $(50 \mu \mathrm{M})$. D. Comparison of the depolarization-induced [Ca $\left.{ }^{2+}\right]$ (Caf/Ry, $n=22,{ }^{*} p<0.001$ by paired $t$ test). Values were normalized to the average $\left[\mathrm{Ca}^{2+}\right]_{;}$transient area evoked by high $\mathrm{K}^{+}$ solution under the control conditions. $E$, The RT-PCR data show that the RyR2 and three subtypes are abundantly expressed in thalamic neurons in VPM/NPL nuclei, while the RyR1 subtype is barely expressed. M, DNA size marker; N, negative control; B, whole-brain cDNA; Th, thalamic VPM/VPL nuclei cDNA.

Pain test and data analysis. Pain tests and data analysis were performed in a double-blinded manner. To prevent any bias, information about the infused drugs was not exposed to either the investigator who performed the pain tests or to the evaluators. Pain responses were recorded with a CCD camera, and the results were independently analyzed by at least two evaluators. A two-tailed $t$ test was used for statistical analysis unless otherwise specified. All values are expressed as means \pm SE. A $p$ value $<0.05$ was taken to be significant.

\section{Results}

Functional RyRs are expressed in TC neurons of VPM/VPL nuclei in mice

To confirm the expression of RyRs and their function as a $\mathrm{Ca}^{2+}$ release channel in TC neurons, we measured the changes in $\left[\mathrm{Ca}^{2+}\right]_{\mathrm{i}}$ using fura-2 AM dye, a ratiometric $\mathrm{Ca}^{2+}$ dye. The cells, acutely dissociated from VPM/VPL nuclei, were identified as neurons based on their cellular morphologies and response to NMDA $(60 \mu \mathrm{M})$. Treating the neurons with a high concentration of caffeine (10 mM), an activator of RyRs, induced an elevation of $\left[\mathrm{Ca}^{2+}\right]_{\mathrm{i}}$ in the $\mathrm{Ca}^{2+}$-free buffer, as well as in the normal extracellular buffer containing $2 \mathrm{mM} \mathrm{Ca}^{2+}$ (Fig. 1A), which indicated that the caffeine-induced $\left[\mathrm{Ca}^{2+}\right]_{\mathrm{i}}$ transient was caused by a $\mathrm{Ca}^{2+}$ release from internal storage. The caffeine-induced $\left[\mathrm{Ca}^{2+}\right]_{i}$ elevation was blocked by pretreating the cells with $50 \mu \mathrm{M}$ ryanodine, a highly selective blocker of RyRs (Fig. $1 B$ ), which indicates that the intracellular $\mathrm{Ca}^{2+}$ increase by caffeine was mediated by a 
A

B

i Before ii slow AHP i

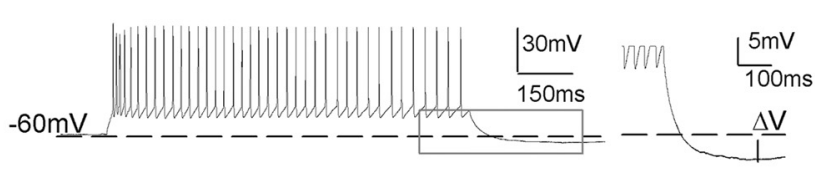

iii Ryanodine

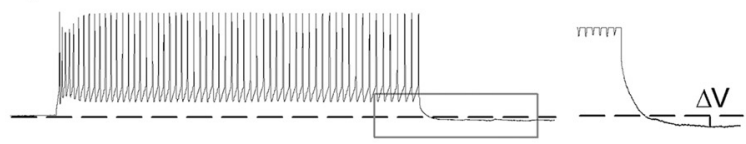

C

i Before

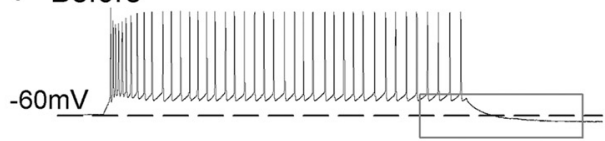

iii caffeine

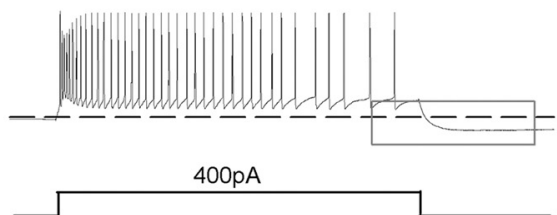

$E$
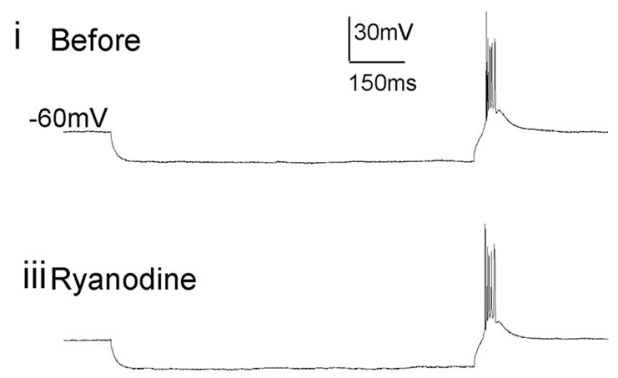

G
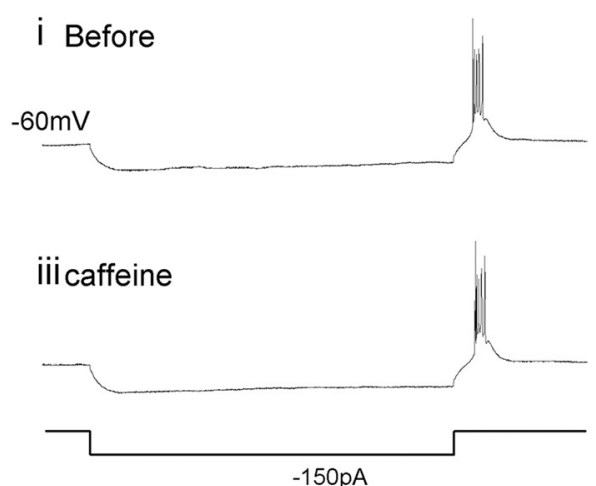

D

iv
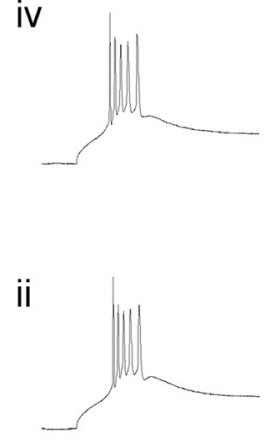

iv

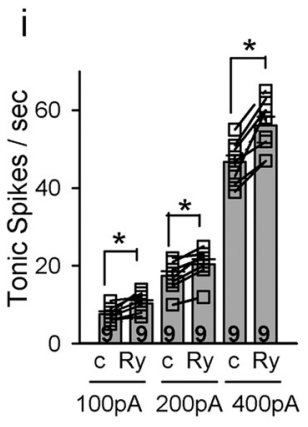

ii

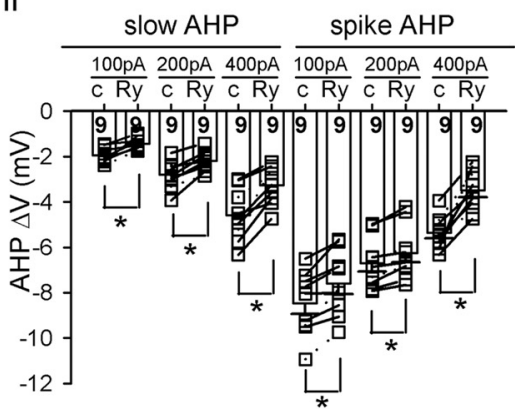

i

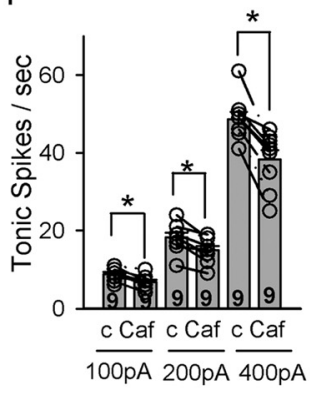

ii $\frac{\text { slow AHP }}{100 \mathrm{pA}} \frac{\text { spopa }}{C \mathrm{CO}} \frac{400 \mathrm{pA} A \mathrm{AHP}}{100 \mathrm{pA}}$

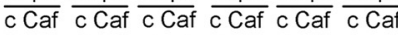

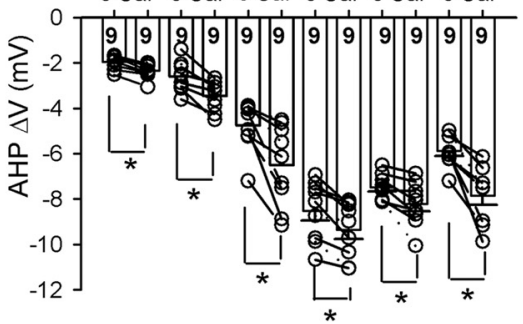

$\mathrm{F}$
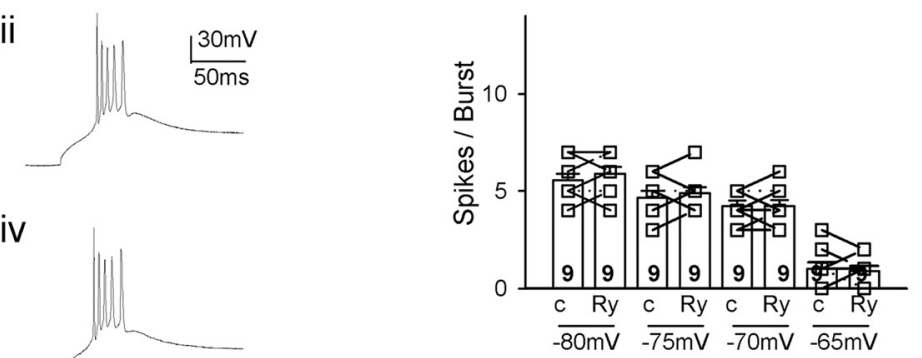

$\mathrm{H}$

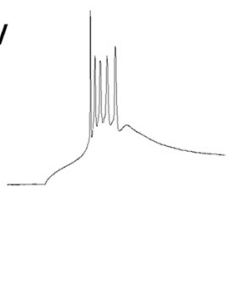

Figure 2. Activity of ryanodine receptors controls the tonic firing rate of TC neurons accompanied by modulation subsequent to hyperpolarization. $A$, Representative traces show the tonic firing of a TC neuron before ( $\boldsymbol{i})$ and after (iii) ryanodine $(50 \mu \mathrm{M})$. ii and $\boldsymbol{i v}$ show the enlarged view of the gray box in $\boldsymbol{i}$ and $\mathrm{iii}$, respectively. $\boldsymbol{B}$, There was a significant increase in the tonic firing rate in TC neurons $(p<0.005$ by paired $t$ test, $n=8)$ and a decrease in AHP in the same sets of neurons $(p<0.001$ by paired $t$ test, $n=8)$ after ryanodine. C, Representative traces show the tonic firing of a TC neuron before (i) and after (iii) caffeine $(0.5 \mathrm{mM})$. $\boldsymbol{D}$, There was a significant decrease in the tonic firing rate in TC neurons $(p<0.001$ by paired $t$ test, $n=7)$ and an enhanced AHP in the same sets of neurons ( $p<0.001$ by paired $t$ test, $n=7$ ) in the presence of caffeine. $\boldsymbol{E}, \mathbf{G}$, Representative traces show the low-threshold burst firing of a TC neuron before (i) and after (iii) adding ryanodine $(50 \mu \mathrm{M})(\boldsymbol{E})$ and caffeine $(\boldsymbol{G})$, respectively. $\boldsymbol{F}, \boldsymbol{H}$, The number of spikes in a burst induced after various hyperpolarizing prepulse membrane potentials before and after ryanodine $(\boldsymbol{F})$ and caffeine $(\boldsymbol{H})$. 
$\mathrm{Ca}^{2+}$ release through RyRs. Subsequently, treating the cells with NMDA $(60 \mu \mathrm{M})$ evoked a $\left[\mathrm{Ca}^{2+}\right]_{\mathrm{i}}$ transient in the same cells, which confirms that these cells were neuronal cells and were sufficiently intact to mediate $\mathrm{Ca}^{2+}$ influx from the extracellular space through NMDA receptors. An application of high $\mathrm{K}^{+}(30$ $\mathrm{mm} \mathrm{KCl}$ ) solution elicited a rapid depolarization of the membrane potential of the neurons, resulting in a large $\left[\mathrm{Ca}^{2+}\right]_{\mathrm{i}}$ transient (Fig. 1C). An application of $0.5 \mathrm{~mm}$ caffeine alone in the extracellular buffer did not induce either a large $\left[\mathrm{Ca}^{2+}\right]_{i}$ transient or a significant increase in the basal level of $\left[\mathrm{Ca}^{2+}\right]_{i}$ in TC neurons. However, the $\left[\mathrm{Ca}^{2+}\right]_{\mathrm{i}}$ transient induced by the $30 \mathrm{mM} \mathrm{KCl}$ solution was larger in the presence of $0.5 \mathrm{~mm}$ caffeine than in the control condition $(167.0 \pm 8.9 \%(n=22), p<0.001$ by paired $t$ test, Fig. $1 D)$. The augmentation of the $\left[\mathrm{Ca}^{2+}\right]_{\mathrm{i}}$ transient by caffeine was abrogated by ryanodine $(70.2 \pm 2.6 \%(n=22), p<$ 0.001 by paired $t$ test), indicating that the larger $\left[\mathrm{Ca}^{2+}\right]_{\mathrm{i}}$ transient in the presence of caffeine was mostly mediated by enhanced $\mathrm{Ca}^{2+}$ release through RyRs.

The RT-PCR data confirmed the expression of the mRNA of the RyR2 and 3 subtypes in VPM/VPL regions in mice, whereas the RyR1 subtype was barely expressed. Next, we investigated the role of RyRs in controlling the firing properties of TC neurons.

\section{Thalamic RyRs control the firing pattern of TC neurons}

We performed whole-cell patch clamping of individual TC neurons in the VPM/VPL nuclei in slices before and after treating with RyR modulators. Tonic firing was induced by injecting various amount of depolarizing currents to the cells held at $-60 \mathrm{mV}$ and low-threshold burst firing was elicited from TC neurons when the membrane potential rebounded to the holding potential $(-60 \mathrm{mV})$ following the hyperpolarizing prepulses for $1 \mathrm{~s}$ (Fig. 2E,F). Panels ii and iv provide enlarged views of the afterhyperpolarization (AHP) in the gray boxes from panels i and iii, respectively. In the presence of ryanodine $(50 \mu \mathrm{M})$, tonic spike numbers of TC neurons were increased by $\sim 22 \%$ ( $46.5 \pm 1.9$ to $56.5 \pm 2.5, p<0.005$ by paired $t$ test, $n=8$; Fig. $2 A, B i$ ) with 400 pA depolarizing current injections. This was accompanied by a decrease in the magnitude of AHP by $\sim 54 \%(-4.52 \pm 0.43 \mathrm{mV}$ to $-2.06 \pm 0.52 \mathrm{mV}, p<0.001$ by paired $t$ test, $n=8$; Fig. $2 \mathrm{Aii}, \mathrm{iv}, \mathrm{Bii})$. In contrast, burst firing was not affected by ryanodine (Fig. $2 E, F$ ). Based on the results of the $\mathrm{Ca}^{2+}$ imaging experiments (Fig. 1C), $0.5 \mathrm{~mm}$ caffeine was used to test the role of enhanced $\mathrm{Ca}^{2+}$ release through the RyRs in TC neurons without altering the basal level of intracellular $\mathrm{Ca}^{2+}$ or depleting the internal $\mathrm{Ca}^{2+}$ stores. Caffeine $(0.5 \mathrm{~mm})$ reduced the tonic spike numbers of TC neurons by $\sim 26 \%$ (from $48.9 \pm 2.4$ to $36.4 \pm 2.7$, $p<0.001$ by paired $t$ test, $n=7$; Fig. $2 C, D i$ ), accompanied by an increase of AHP of $\sim 50 \%(-5.45 \pm 0.46 \mathrm{mV}$ to $-8.15 \pm 0.28$ $\mathrm{mV}, p<0.001$ by paired $t$ test, $n=7$; Fig. 2 Cii, $i v, D i i)$. On the other hand, caffeine did not affect the low-threshold burst firing (Fig. 2G,H).

There was no difference in the resting membrane potential $(-60.24 \pm 5.63 \mathrm{mV}$ vs $-58.74 \pm 6.71 \mathrm{mV}[n=7] ;-59.16 \pm$ $6.01 \mathrm{mV}$ vs $-61.03 \pm 7.26 \mathrm{mV}[n=7])$ or in input resistance $(167.03 \pm 31.45 \mathrm{M} \Omega[n=7]$ vs $171.49 \pm 25.33 \mathrm{M} \Omega[n=7]$; $184.70 \pm 34.15 \mathrm{M} \Omega[n=7]$ vs $158.91 \pm 29.61 \mathrm{M} \Omega[n=7])$ before and after treating the neurons with ryanodine or caffeine, respectively. Similarly, the amplitudes and half-widths of the action potentials in burst or tonic firing were not different before and after applying these drugs.

Our data show that $\mathrm{Ca}^{2+}$ release through RyRs controls the tonic firing rate of TC neurons, probably via regulating the $\mathrm{Ca}^{2+}$ activated AHP, which further led us to pursue its physiological
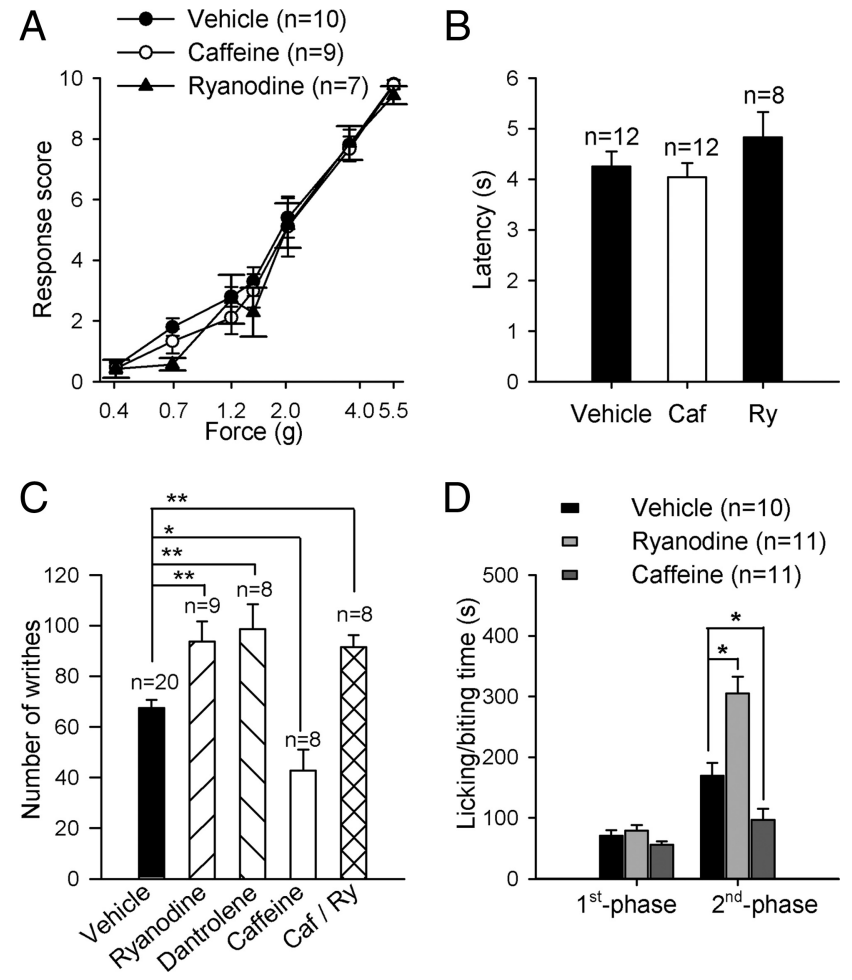

Figure 3. Inflammatory pain responses are modulated by RyRs in thalamocortical relay nucleus. $\boldsymbol{A}, \boldsymbol{B}$, Pain responses to noxious mechanical stimuli $(\boldsymbol{A})$ and paw withdrawal latencies to radiant heat stimuli (intensity 40$)(B)$ in mice with thalamic infusion of vehicle, caffeine $(0.5$ $\mathrm{mm})$, and ryanodine $(50 \mu \mathrm{m})$. $C$, Visceral pain responses triggered by acetic acid injection into mice with thalamic infusion of vehicle, $50 \mu \mathrm{m}$ ryanodine, $50 \mu \mathrm{m}$ dantrolene, and $0.5 \mathrm{~mm}$ caffeine, and the coapplication of caffeine and ryanodine. The number of writhes was measured for 20 min following intraperitoneal acetic acid injection. D, Pain responses to injection of $2.0 \%$ formalin in the hindpaws of mice. Time spent licking/biting on the formalin-injected paw was summed in the first phase $(0-10 \mathrm{~min})$ and second phase $(10-60 \mathrm{~min}){ }^{*} p<0.01,{ }^{* *} p<0.05$.

functions in vivo. The VPM/VPL nuclei for which we recorded the firing properties of TC neurons are in the pain signal transmission pathway to the cortex. Therefore, we examined whether the altered firing properties of TC neurons by RyR modulators play a role in pain signal processing.

Thalamic RyRs modulate the chemical-induced inflammatory pain responses, but not acute pain responses, in vivo

To determine the role of the thalamic RyRs in pain signal processing, we compared the pain behaviors of mice treated with an infusion of an antagonist or an agonist for RyRs into the TC relay nuclei. First, we performed acute pain assays. In the mechanical pain test, the response scores for a broad range of mechanical stimuli by von Frey filaments were not different among the mice treated with a thalamic infusion of vehicle, caffeine or ryanodine, respectively (Fig. 3A). There was no difference in thermal pain responses in the radiant heat assay (Hargreaves's test, Fig. $3 B$ ), either. These results suggest that these acute pain responses are not affected by the activity of thalamic RyRs in mice.

We next examined the response to the inflammatory pain induced by acetic acid or formalin injections. Acetic acid $(0.6 \%)$ was injected into the peritoneal cavity of the mice to induce visceral pain using the method previously described (Kim et al., 2003). The visceral pain responses were greater in mice infused with either ryanodine $(50 \mu \mathrm{M})$ or dantrolene $(50 \mu \mathrm{M})$, RyR blockers, into the TC relay nuclei than in mice infused with vehicle $(p<0.05$; Fig. 3C). In addition, the mice administered an infu- 
sion of caffeine into the same target region showed significantly decreased visceral pain responses compared with the vehicletreated mice $(p<0.01$; Fig. $3 C)$. In the mice treated with a coapplication of caffeine and ryanodine, the visceral pain responses were similar to those with ryanodine or dantrolene, suggesting that the analgesic effect of caffeine mostly occurred through RyRs. In the formalin-induced pain test, subcutaneous injection of $2 \%$ formalin into a hindpaw reportedly produces a biphasic pain response of the injected paw in the mice (Rosland et al., 1990; Puig and Sorkin, 1996). The first phase response $(0-10 \mathrm{~min})$ is generally attributed to acute pain occurring by direct activation of nociceptive fibers. The second phase $(10-60 \mathrm{~min})$ is considered to be persistent pain resulting from tissue inflammation and might be affected by the central and/or peripheral sensitization of nociceptive neurons. There was no difference in the first phase pain responses in the mice administered an infusion of ryanodine or caffeine compared with the mice with vehicle treatment. In contrast, the mean duration of the pain behavior in the second phase was significantly increased in the mice with the infusion of ryanodine, whereas it was decreased in the mice with the infusion of caffeine into TC relay nuclei $(p<0.01$; Fig. $3 D)$. These data together show that the activity of thalamic RyRs may control inflammatory pain processing in the thalamus.

\section{Discussion}

Here it has been demonstrated that thalamic RyRs control the firing pattern of TC neurons and may affect inflammatory pain sensory processing in the thalamus.

\section{Thalamic RyRs control the tonic firing rate of TC neurons in mice}

Our data show that RyR2 and RyR3 subtypes are expressed in VPM/VPL nuclei and that blocking them increases the tonic firing rate of TC neurons of these nuclei in mice. On the other hand, another study reported that RyRs are expressed in rat thalamic neurons and blocking them shifted the firing pattern of TC neurons of dorsolateral geniculate nucleus from the regular firing of single action potentials to spike clusters (Budde et al., 2000). This discrepancy might come from the difference in species of the experimental animals or in the target nuclei in the TC relay region. RyR 2 and 3 subtypes are known to release $\mathrm{Ca}^{2+}$ via CICR in response to the $\mathrm{Ca}^{2+}$ influx through voltage-gated $\mathrm{Ca}^{2+}$ channels. Functional coupling between L-type $\mathrm{Ca}^{2+}$ channels and RyRs were first found in muscle cells and later in neurons (Chavis et al., 1996). We previously confirmed the expression of L-type $\mathrm{Ca}^{2+}$ channels $\left(\mathrm{Ca}_{\mathrm{v}} 1.2\right.$ and $\left.\mathrm{Ca}_{\mathrm{v}} 1.3\right)$ in VPM/VPL nuclei and showed that blocking them increased the tonic firing rate in TC neurons (Cheong et al., 2008), which is in accord with our current findings.

A previous study suggested that RyR-mediated $\mathrm{Ca}^{2+}$ release is closely linked to SK (small-conductance $\mathrm{Ca}^{2+}$-activated $\mathrm{K}^{+}$) channel opening in the somatodendritic region of cerebellar Purkinje cells (Kakizawa et al., 2007). Our data show a similar functional coupling between RyRs and SK channels in TC neurons. Here we showed that blocking RyRs increased the tonic firing rate and a diminished AHP (Fig. 2). We recently reported the expression of SK2 and SK3 subtypes, mediators of $\mathrm{Ca}^{2+}$-activated AHP, in VPM/VPL nuclei and demonstrated that blocking SK channels increased the tonic firing of TC neurons with no effect on burst firing (Cheong et al., 2008). Therefore, $\mathrm{Ca}^{2+}$ release through RyRs controls the firing rate of TC neurons via regulating subsequent $\mathrm{Ca}^{2+}$-activated AHP (Stocker, 2004).
Together, these data strongly suggest that $\mathrm{Ca}^{2+}$ influx through L-type $\mathrm{Ca}^{2+}$ channels activated by membrane depolarization triggers additional $\mathrm{Ca}^{2+}$ release from internal storage through RyRs, which in turn activates $\mathrm{Ca}^{2+}$-activated SK channels mediating AHP. This series of events would decrease the tonic firing rate of TC neurons. In addition, these might affect the firing pattern or the transition between the two firing modes in vivo.

\section{Inhibitory role of thalamic CICR via RyRs in inflammatory pain signal transmission}

The findings predict altered tactile sensation due to the altered $\mathrm{Ca}^{2+}$ release via modulating RyRs in TC neurons. Although we do not know whether any of the neurons tested were nociceptive, it is possible that modulating RyRs in VPL would alter pain behavior (McCormick and von Krosigk, 1992). The mice with infusion of caffeine into the thalamic relay nuclei indeed exhibited a reduction of inflammatory pain responses, but not acute pain responses. Previous studies also reported that the changes in TC properties altered only inflammatory pains, but not acute pains although none of these provided the exact mechanism behind this (Kim et al., 2003; Miyata et al., 2003; Cheong et al., 2008). It is not clear however why behavioral responses to acute pain were unaffected unless the behaviors tested were primarily the result of spinal/brainstem-mediated reflexes.

It is well known that caffeine reduces the threshold for $\mathrm{Ca}^{2+}$ activation curve of RyRs, with the result that a small amount of $\mathrm{Ca}^{2+}$-influx causes a large $\mathrm{Ca}^{2+}$ release via RyRs (Shankar et al., 1995; Hayek et al., 2000). Caffeine has long been used as an adjuvant analgesic agent, especially for chronic and severe pain (Sawynok and Yaksh, 1993). Its analgesic effect has usually been attributed to its function as an adenosine receptor antagonist (Sawynok and Yaksh, 1993). Our data suggest that the analgesic effect of caffeine might be at least partly due to its effect on RyRs in TC relay nuclei.

Here, we have demonstrated that RyRs control the tonic firing rate in TC neurons and modulate behavioral responses to inflammatory pain. These results provide new insight into how the $\mathrm{Ca}^{2+}$ release from internal stores via RyRs may contribute to the control of thalamic pain processing, and raise a potential new target for developing pain medications.

\section{References}

Beenhakker MP, Huguenard JR (2009) Neurons that fire together also conspire together: is normal sleep circuitry hijacked to generate epilepsy? Neuron 62:612-632.

Berridge MJ, Bootman MD, Roderick HL (2003) Calcium signalling: dynamics, homeostasis and remodelling. Nat Rev Mol Cell Biol 4:517-529.

Budde T, Sieg F, Braunewell KH, Gundelfinger ED, Pape HC (2000) $\mathrm{Ca}^{2+}$ induced $\mathrm{Ca}^{2+}$ release supports the relay mode of activity in thalamocortical cells. Neuron 26:483-492.

Chapman CR, Casey KL, Dubner R, Foley KM, Gracely RH, Reading AE (1985) Pain measurement: an overview. Pain 22:1-31.

Chavis P, Fagni L, Lansman JB, Bockaert J (1996) Functional coupling between ryanodine receptors and L-type calcium channels in neurons. Nature 382:719-722.

Cheong E, Lee S, Choi BJ, Sun M, Lee CJ, Shin HS (2008) Tuning thalamic firing modes via simultaneous modulation of T- and L-type $\mathrm{Ca}^{2+}$ channels controls pain sensory gating in the thalamus. J Neurosci 28:1333113340.

Furuichi T, Furutama D, Hakamata Y, Nakai J, Takeshima H, Mikoshiba K (1994) Multiple types of ryanodine receptor/ $\mathrm{Ca}^{2+}$ release channels are differentially expressed in rabbit brain. J Neurosci 14:4794-4805.

Hargreaves K, Dubner R, Brown F, Flores C, Joris J (1988) A new and sensitive method for measuring thermal nociception in cutaneous hyperalgesia. Pain 32:77-88. 
Hayek SM, Zhu X, Bhat MB, Zhao J, Takeshima H, Valdivia HH, Ma J (2000) Characterization of a calcium-regulation domain of the skeletal-muscle ryanodine receptor. Biochem J 351:57-65.

Kakizawa S, Kishimoto Y, Hashimoto K, Miyazaki T, Furutani K, Shimizu H, Fukaya M, Nishi M, Sakagami H, Ikeda A, Kondo H, Kano M, Watanabe M, Iino M, Takeshima H (2007) Junctophilin-mediated channel crosstalk essential for cerebellar synaptic plasticity. EMBO J 26:19241933.

Kim C, Jun K, Lee T, Kim SS, McEnery MW, Chin H, Kim HL, Park JM, Kim DK, Jung SJ, Kim J, Shin HS (2001) Altered nociceptive response in mice deficient in the alpha(1B) subunit of the voltage-dependent calcium channel. Mol Cell Neurosci 18:235-245.

Kim D, Park D, Choi S, Lee S, Sun M, Kim C, Shin HS (2003) Thalamic control of visceral nociception mediated by T-type $\mathrm{Ca}^{2+}$ channels. Science 302:117-119.

McCormick DA, von Krosigk M (1992) Corticothalamic activation modulates thalamic firing through glutamate "metabotropic" receptors. Proc Natl Acad Sci U S A 89:2774-2778.

Miyata M, Kashiwadani H, Fukaya M, Hayashi T, Wu D, Suzuki T, Watanabe M, Kawakami Y (2003) Role of thalamic phospholipase C[beta]4 mediated by metabotropic glutamate receptor type 1 in inflammatory pain. J Neurosci 23:8098-8108.
Pape HC, Munsch T, Budde T (2004) Novel vistas of calcium-mediated signalling in the thalamus. Pflugers Arch 448:131-138.

Peschanski M, Mantyh PW, Besson JM (1983) Spinal afferents to the ventrobasal thalamic complex in the rat: an anatomical study using wheatgerm agglutinin conjugated to horseradish peroxidase. Brain Res 278: $240-244$.

Puig S, Sorkin LS (1996) Formalin-evoked activity in identified primary afferent fibers: systemic lidocaine suppresses phase-2 activity. Pain 64:345-355.

Rosland JH, Tjølsen A, Maehle B, Hole K (1990) The formalin test in mice: effect of formalin concentration. Pain 42:235-242.

Sawynok J, Yaksh TL (1993) Caffeine as an analgesic adjuvant: a review of pharmacology and mechanisms of action. Pharmacol Rev 45:43-85.

Shankar VS, Pazianas M, Huang CL, Simon B, Adebanjo OA, Zaidi M (1995) Caffeine modulates $\mathrm{Ca}^{2+}$ receptor activation in isolated rat osteoclasts and induces intracellular $\mathrm{Ca}^{2+}$ release. Am J Physiol 268:F447-F454.

Sherman SM, Guillery RW (1996) Functional organization of thalamocortical relays. J Neurophysiol 76:1367-1395.

Stocker M (2004) Ca(2+)-activated K+ channels: molecular determinants and function of the SK family. Nat Rev Neurosci 5:758-770.

Willis WD, Westlund KN (1997) Neuroanatomy of the pain system and of the pathways that modulate pain. J Clin Neurophysiol 14:2-31. 